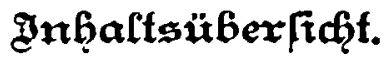

\section{Crfies 8ud.}

Daseitalter be Gumanismu

Einleitendés . . . . . . . . . . . . . . 1-4

1. Sap.: Яüdblid unb übergang . . . . . . . . . . . 5-29

2. Sap.: Die Infänge ber geleğtten Oejđidttidrcibung . . . . 30-90

3. Sap.: Raijer Mazimintian I. unb bie nationale ofejdidtidreibung 91-142

4. Sap.: Die territoriale und ftäbtifde Bejdiditidreibung . . . 143-178

5. Rap.: Die bcutfde Be[didtthdreibung unter ben Eintwirtungen ber Meformation . . . . . . . . . . . . . 178-338

\section{3weites 8ud. \\ Das Beitalter ber Begenteformation unb bes Stlliftanbes.}

Q14gemeines $339-344$

Die Siftoriomathie . . . . . . . . . . . . . . . . 344

Die Efronologie . . . . . . . . . . . . . . . $346-347$

Die Beitgeididhte . . . . . . . . . . . . . . . . 347-365

Die beutide Beididatc. . . . . . . . . . . . . . . 365-372

Die Ranbergejdidte . . . . . . . . . . . . . . . $372-464$

\section{Drittes Dud.}

Da polghiforilde Bcitalter. Bom $\mathfrak{A}$ ugange bes grofen beutimen siege bis a friebri申 ben roben.

Qugemeine . . . . . . . . . . . . . . . . . 465-471

1. Stap.: Die Uniberjalgejđjidte . . . . . . . . . . . 472-489

2. Sap.: Die Beitgejめiळte . . . . . . . . . . . . . 489-561

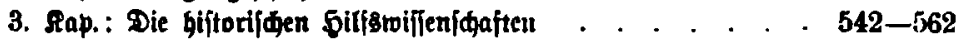

4. Slap.: Die beutide Gejdidte . . . . . . . . . . 563-687

5. Sap.: Die Sanbesgejdidte . . . . . . . . . . . . 687-732

6. Stap.: Die alte, dic Mirdyen= unb Siteraturgejdidgte . . . . 733-744 


\section{Bierte 8um.}

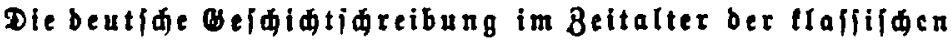

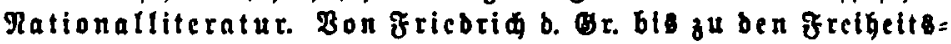
tricgen.

Geite IU⿴囗十еmeines . . . . . . . . . . . . . . . . . . 744-756

1. Rap.: Die hliftorijien Бilfsivifienidaften . . . . . . 756-772

2. Sap.: Die allgcmeine Bejaidte. Dic Aulturgeididite. Die \$gillo. jopgie ber Bejdidte.

1. Die allgemcine Bejdidte . . . . . . . . 772-848

2. Die Multurgefdidte. Die \$hilojophie ber Bcjøidte $848-869$

3. Siap.: Dic Staatengejdidte . . . . . . . . . . . 869-886

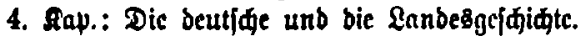

1. Dic beutidic Bejdifitc . . . . . . . . . 887-924

2. Dic Lanbegcididite . . . . . . . . . . 925-945

5. Rap.: Die ncuete unb bic Bcitge|didhtc . . . . . . . 946-966

6. Siap.: Die alte Bejfidte . . . . . . . . . . . 966-974

\section{ซ̛̉üftes Pư.}

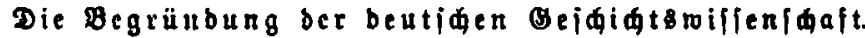

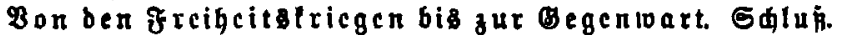

Ingcmeines . . . . . . . . . . . . . . . . . . 975-977

1. Borbereitende日. - Die Siomantija Sdule. - Jalob Grimm. -

Sdjelling und \$egel . . . . . . . . . . . . . . 977-987

2. Die hiftorifde Sdulc. - B. Mtiebuhr . . . . . . . 987-1007

3. Dic Mouumenta Germaniae historica. - Die beutífe und bic mittclaltertide (Bejđidtc . . . . . . . . . . . 1010-1040

4. Scopolb von Yianle unb feine n̈lteron Sdjiilex . . . . . 1041-1061

5. Die Weibelberger હquile . . . . . . . . . . . . 1061-1076

6. Edlübetradtungen . . . . . . . . . . . . . . . 1076-1081 